\title{
On the Cultivation of Students' Innovative Ability in Higher Vocational Computer Teaching
}

\begin{abstract}
Li Zhang, Hongchang Wei
Jiangxi Vocational College of Mechanical \& Electrical Technology, Jiangxi, Nanchang,330013

3107000933@qq.com

ABSTRACT

With the rapid change of the world, the continuous development of science and technology, and the development of society at different stages, the requirements for talents are different. Now, comprehensive innovative talents are needed. In particular, the computer specialty in higher vocational colleges should pay more attention to the cultivation of innovative talents. However, due to the shortcomings of our education mechanism, the ability of colleges and universities to cultivate innovative talents is generally insufficient. This paper will analyze the teaching status of computer major in higher vocational colleges, elaborate the importance of cultivating students' innovation ability, analyze the effectiveness of the strategy of cultivating students' innovation ability in computer major of higher vocational colleges, and put forward suggestions on how to cultivate students' innovation ability.
\end{abstract}

Keywords: Computer science, innovation ability training, higher vocational colleges

\section{浅谈高职计算机教学中学生创新能力的培养}

\author{
张莉 魏洪昌
}

\author{
江西机电职业技术学院 江西南昌 330013 \\ 3107000933@qq.com
}

\section{摘要}

当今世界瞬息万变, 科学技术不断发展, 社会发展到不同的阶段, 对于人才的要求也是不一样的, 如今就需要 综合型的创新人才。尤其是高职院校的计算机专业, 应该更加重视创新型人才的培养。但是由于我国的教育机 制一直存在缺陷, 高校培养创新型人才的能力普遍不足。本文将分析高职院校计算机专业的教学现状, 阐述培 养学生创新能力的重要性, 分析目前高职院校计算机专业培养学生创新能力策略的有效性, 并对如何培养学生 的创新能力提出建议。

\section{关键词: 计算机专业; 创新能力培养; 高职院校}

\section{1. 前言}

高职院校教育承担了一部分高等院校教育无法 承担的责任, 对于就业来说非常重要, 也是培养综合 型人才的重要基地。计算机教学是高职教育中很重要 的一部分, 促进学生专业技能提高, 并鼓励他们加以 运用, 对于学生的创新能力培养有着重要意义, 实现 院校培养新型人才的目标, 满足新时期社会对人才的 要求。因此, 计算机专业应该把重心放在学生的创新
能力培养上面, 提升学生的综合素质, 推动学校的发 展，满足社会就业需求。

\section{2. 计算机专业教学存在的问题}

\section{1. 学生的基础水平不一}

由于客观和主观的因素, 高职院校的学生在计算 机基础文化知识和素养方面存在着较大的差异, 这些 差异对高职院校的计算机教学有一定程度的影响。由 于计算机专业的特殊性, 学生们在学习的时候需要掌 
握一些基本的计算机知识，同时也要有学习兴趣，而 这些差异的存在, 就导致一部分基础较差的学生失去 继续学习的信心，也不再主动探索和了解，甚至可能 会自暴自弃。而高职院校本身就和本科院校存在着一 定的差距, 高职院校的管理和学习氛围的培养都和本 科院校有差距, 在学校条件和自我知识基础的共同影 响下, 有一部分学生丧失了自我学习的意识和能力。

\section{2. 师资力量有限}

高职院校培养学生的能力, 一部分取决于学校的 基础设施, 一部分还取决于师资力量。专业能力过硬 的师资团队培养出专业技能过硬学生的可能性更大。 目前我们国家高职院校计算机专业师资力量不足，一 是计算机专业老师数量严重缺乏, 存在着非计算机专 业出身的老师代教课程, 二是一部分老师专业能力不 够, 没有更新知识体系。这些都是非常不利于学生学 习的因素, 当学生无法从老师那里获取知识, 满足自 我的学习需求的时候, 就会产生厌弃的心理, 不利于 学生学习兴趣的培养。由此可见, 师资力量不足将对 学生的学习产生非常重大的影响, 高职院校除了注重 基础设施建设, 还应该重视教师团队的培养。

\section{3. 教学理念落后}

计算机专业的教学, 除了理论教学, 更多的是要 培养学生的实践能力。目前我们国家很多高职院校的 计算机专业教学还停留在以前的教学方式和理念, 没 有及时更新。而很多学生对于传统的教学方式已经有 了一定的抵触心理, 因此在学习的时候就无法摆正心 态, 无法获取更多的计算机知识。再有学校的评价机 制也还是老一套, 单一的评价方式只注重学生的考试 成绩, 忽略了学生的创新能力和实践能力, 但是计算 机专业本身就具有很强的实践性, 只掌握理论知识是 无法适应社会更新速度的。

\section{4. 教学环境和条件不好}

很多高职院校都洞察到了当今信息化社会计算 机技术人才的需求, 开始重视计算机教学, 但是本身 基础教学设备的落后限制了高校的教学能力, 一方面 是本身就无法满足学生们越来越高的计算机应用水 平, 另一方面是学生的数量在不断的增加, 教学资源 无法与之匹配。高职院校只有在掌握了最新的专业知 识, 拥有最新全面的设备和教学软件, 才能够使学生 能够真正体会到计算机技术, 学习到相关的分析能力 和应用能力, 增强就业竞争力。

\section{3. 学生创新能力培养的重要性}

\section{1. 适应结合社会的发展}

当前社会的高速发展，计算机已渗透入各个行业， 掌握计算机的技术已经成为了每一个学生生存发展 的必备工具, 计算机可以提高学生工作的效率和质量,
所以各行各业在招聘时对于学生掌握计算机的程度 有所要求。目前在各个岗位的需求中我们发现, 大家 已经默认都已经掌握了基本的计算机能力。但我们需 要明确的是，为了使社会发展的更好，不能仅仅的局 限在于如何学会使用计算机, 要学会如何在计算机这 个行业进行创新。不仅仅是计算机技术本身的创新, 而是通过这种创新来提升学生们自主探索的能力, 扩 展他们的思维。让他们在工作生活中遇到问题时不仅 仅局限思考，而是有多方位的角度。目前高职院校以 这样的目的来培养创新人才，适应整个社会发展的需 求。

\section{2. 以综合素质来带动学生的创新能力}

目前, 高职计算机的教学任务主要体现在于学生 们掌握计算机的技术，使得学生们在工作生活中能够 运用计算机的能力灵活地处理各类问题, 为学生们进 入职业中提供一项基本的技能。但是目前的学习不能 仅仅表现在于掌握计算机的能力，而应适应社会的发 展, 更注重创新能力的培养, 在创新计算机的过程之 中, 可以培养学生们自主思维的能力, 体现不同学生 的个性。创新思维是一个综合性的思维, 它需要运用 到学生们的各类器官, 以及需要结合学生们的运算逻 辑能力。提高学生们的整体思维能力, 有利于提高他 们吸收计算机的基本知识, 使他们有更好的发展。

\section{4. 计算机教学中学生创新能力的培养}

\section{1. 教学方式的改进}

教师在教学过程中, 要以教学大纲为基础, 让学 生打下扎实的基础。同时, 也要悉心编排教学内容, 让教学过程井井有条, 避免教学时间的浪费, 建立完 整的教学体系。要想培养学生的创新能力, 仅仅使用 传统的教学方式是完全不够的。计算机教师需要不断 更新自己的教学方式, 根据教学内容来选择有针对性 的教学方式, 继而提升学生的计算机能力。

\section{1. 1. 进行理论知识教学}

计算机基础知识教学中有许多理论知识。在传统 的教学中, 学生常常被要求死记硬背一些定义和常识。 误导学生认为学习计算机基础就是要把这些理论知 识背下来, 从而脱离实际操作, 花费大量的时间和精 力去记忆理论知识只能应付一些考试, 但当学生面对 计算机实践操作时, 却感到茫然, 从而消除了学习计 划对计算机的兴趣。然而通过课程改革, 复杂而难懂 的知识变得通俗易懂, 在此同时, 还能提高学习质量, 全方位掌握知识, 提高计算机学习的趣味性, 培养学 生主动学习的能力。

\subsection{2. 进行实践操作教学}

高职计算机的教育过程中进行实践活动是非常 有必要的。科学的实践活动能够进一步强化学生对计 
算机知识的理解和掌握在实践教学中, 培养学生的操 作能力和问题解决能力, 在这个过程中学生往往会形 成更强的创新意愿和创新意识, 最终培养出更强的创 新能力。高职计算机专业教师不仅要在教学过程中对 学生的创新意识进行培养, 还应积极引导学生在实践 中应用知识理论, 这样学生就会进一步认识和理解理 论, 进而产生创新意识、进行创新活动。通过实践活 动, 学生能够更加牢固地掌握知识, 提升自身的创新 能力，同时两者之间又具有互相推动的作用，进而实 现创新能力和知识水平的不断提升。

\section{2. 改革教学方法}

\subsection{1. 强化教学实践培养学生自主学习能力}

在讲授一些简单、基础的软件时, 教师起连接学 生与知识的作用。对那些容易出错的内容进行详细讲 解, 从而充分培养学生的学习自主性。充分安排学生 进行实训练习, 使学生在计算机实践过程中能够独立 学习, 理解学习内容并加以运用, 为学生今后相关知 识的自主学习打下了基础。例如, 在教 Word 应用教 程时, 我先在大屏幕上演示了一份用 Word 编辑的美 观、精致的晚报，晚报中既有各式各样的文字、图片， 又有各种不同的表格, 学生们看后立刻发出惊叹的声 音, 各自展开了充分的想象空间, 思考着如何来完成 这个设计。在这样浓烈的学习气氛中, 我给学生概括 讲解 Word 所具有的强大功能, 学生马上产生了强烈 的求知欲, 个个跃跃欲试, 这就为后面授课的顺利进 行做好了准备。

\subsection{2. 运用任务驱动教学法激发创造性思维}

教师在培养学生的创新性思维中起着至关重要 的作用。在教学过程中, 教师要以创新思想为指导, 引导学生参与创造性活动, 培养学生的创造性, 引导 学生全方位思考问题的解决方法, 防止思维僵化。在 教学每一节课或每门课之前给学生演示本课要完成 的任务, 用完成任务作为动力, 驱动学生在完成任务 的过程中达到自主学习和掌握知识的目的。通过这样 的教学方式, 既完成了教学任务, 又提高了学生的思 维能力, 激发了学生学习的求知欲和好奇心, 培养了 学生敏锐的观察力和丰富的想象力。因此, 高职计算 机专业教师应当采取各种有效措施激发学生的学习 积极性和兴趣, 在实际中创设问题情境能够有效地激 发学生兴趣, 在特定的创新氛围中能够更好地传授知 识, 加之多媒体等教学设施能够通过图片和视频更好 地吸引学生, 使学生的创新能力能够得更好培养和大 幅提升。

\subsection{3. 实施 “研究性学习” 教学方法激发创 新积极性}

探究型学习是通过学生尝试对问题解决的过程, 来获取知识、提升能力、形成价值观的学习方式, 强
调对所学知识、技能的实际运用, 注重学习的过程和 学生的实践与体验。教师需鼓励学生以解决问题为目 的, 进行探究性学习。计算机科学与其他科目相比, 可操作性更强、发展更加迅速, 在教学过程中若采用 研究性学习方法, 将更便于学生发现问题, 提出新的 疑问, 在学生无法解决问题的情况下, 教师能引导教 学, 探讨解决问题的方式。

质疑、探究、求知、创新意识是优秀人才应当具 备的重要品质, 只有这样的人才才能够在工作岗位上 推陈出新, 进而推动企业发展和社会进步。高职院校 要想培养出更多的计算机专业合格人才, 就应当强化 对计算机专业学生创新能力的培养, 组织学生探究性 学习, 进而为社会输送更多的高素质人才。

\section{3. 对教材进行改革}

针对于课本教材进行改革，第一点，要确定以人 为本的新课程思想, 在选择教材课本的时候时刻记住 以学生为本。教材的组织需要是根据学生的能力进行, 或者是考虑学生的兴趣, 侧重学生的学习经验的, 这 样才可以让学生更容易接受知识, 让学生愿意去学习 这些知识。第二点, 教育是要符合市场需求的, 发展 人才的目标就是促进社会的发展, 而且学生学习的知 识内容是要和市场的最新知识技术同步, 这样才可以 给市场培养出需要的人才, 这也就意味着教材需要除 了需要专业外, 还需要符合现代特色。第三点, 教材 是教育的工具, 让学生学会只知识, 所以对于教材的 质量一定要严格把控, 具体到课程目标和课程研究等 方面, 让学生可以在这个目标写进行学习知识, 理解 书本上的理论知识, 再把知识运用到解决问题上。

一个国家或者说一个民族是否具有实力, 这需要 考虑很多方面, 但是这些实力都需要通过创新进一步 发展, 停滞不前就会弱后, 实力也就会弱后。对于一 个国家怎样去整体提升创新意识, 这就需要教育进行 培养, 所以教育要进行创新, 要进行改革。而培养创 新能力的重点就是需要有创新的教育。在传统教育上 不断进行创新, 改变以往学生只会理论知识, 不会创 新的现象。通过教育改革, 培养出具有创新意识的人 才, 培养出具有自学能力的人才, 促进国家的发展。

\section{5. 结论}

从上世纪计算机诞生之初, 到现在, 计算机已经 发展了几个时代, 每一次发展都是技术的大创新大跃 进, 随着日新月异的计算机技术发展, 社会所需要的 计算机人才也越来越多。依托计算机技术不断更迭并 发展迅速的特点, 社会发展需要更多具有创新能力的 计算机专业人才, 只有这样才能符合计算机时代对人 才的要求。因此, 高校在对计算机类学生的培养过程 中一定要重视并培养他们的创新能力, 通过不断的挖 掘当下教学的问题并积极的进行解决, 从而引导进行 创新教育, 才能真正的培养出高素质的创新人才, 才 能助推我国经济社会的发展。 


\section{REFERENCES}

[1] Tang Suqin. On the training strategy of the innovation ability of high vocational computer teaching students [j]. New curriculum: 2, 2016 (7): $158-159$

[2] Chen Lanlan. On the training path of students' innovation ability in computer teaching of Higher Vocational Colleges [j]. Intelligence, 2016, (28).170170172

[3] Rosa, huangxiaoping, huanglijuan. The cultivation of the innovation ability of high vocational computer teaching students [j]. Journal of Changsha Railway College (SOCIAL SCIENCE EDITION).2014, (1).261-262

[4] Kuang Wenbing. On the cultivation of students' innovative ability in computer teaching in Higher Vocational Colleges [j]. Computer knowledge and technology, 2016, (34).151-152

[5] Caoyanjin. A study on the cultivation of innovation ability of high vocational computer teaching students [j]. Heilongjiang Science and technology information, 2016, (5).158-158159

[6] Mr. brunxin. On the cultivation of students' innovative ability in computer teaching in Higher Vocational Colleges [j]. Education and occupation, 2010, (27).145-146

[7] Nur Ellie Elken, Wen Huan. Analysis of the teaching reform of software engineering course based on innovation ability training [j]. Scientific consultation.2020, (33).102

[8] Zhou Kejun, Zhang Cong, and heartbreaking. On the cultivation of students' innovative ability in computer teaching in Higher Vocational Colleges [j]. Chinese information.2017, (10). 150

[9] Ma Xia. On the cultivation of students' innovative ability in computer teaching in Colleges and universities [j]. Computer CD software and application, 2014, (13).246-246248

[10] Wang yingbang. The strategy of cultivating the innovation ability of computer teaching students in Colleges and universities [j]. The guide to the prosperity of science and technology, 2014, (8).313313

[11] Zhao Limin. On the cultivation of students' innovative ability in computer teaching in Colleges and universities [j]. Education and occupation, 2007, (3).110-111

[12] Zheng Weiyin, he Bo. The way to cultivate students' innovation ability in computer teaching of higher vocational education [j]. New campus (last xunlao).2016, (5).104-105

[13] He party power. On the cultivation of students' innovative ability in computer teaching [j]. Youth and society. Education research at home and abroad, 2009, (5).150-151

[14] Deng Wanfu. On the cultivation of students' innovation ability in computer teaching in Higher Vocational Colleges [j]. Curriculum Education Research (new teacher teaching).2013, (24).235-235

[15] Meng Haoran. The research on the cultivation of the innovation ability of high vocational computer teaching students [j]. Electronic magazine in the new education era (Teacher Edition).2015, (5).12-12 